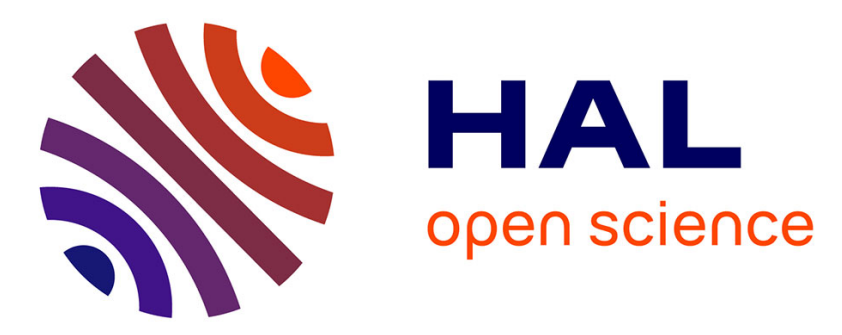

\title{
Effects of UV-dechloramination of swimming pool water on the formation of disinfection by-products: A lab-scale study.
}

Nicolas Cimetiere, Joseph de Laat

\section{- To cite this version:}

Nicolas Cimetiere, Joseph de Laat. Effects of UV-dechloramination of swimming pool water on the formation of disinfection by-products: A lab-scale study.. Microchemical Journal, 2014, 112, pp.34-41. 10.1016/j.microc.2013.09.014 . hal-00916500

\author{
HAL Id: hal-00916500 \\ https://hal.science/hal-00916500
}

Submitted on 10 Dec 2013

HAL is a multi-disciplinary open access archive for the deposit and dissemination of scientific research documents, whether they are published or not. The documents may come from teaching and research institutions in France or abroad, or from public or private research centers.
L'archive ouverte pluridisciplinaire HAL, est destinée au dépôt et à la diffusion de documents scientifiques de niveau recherche, publiés ou non, émanant des établissements d'enseignement et de recherche français ou étrangers, des laboratoires publics ou privés. 


\title{
Effects of UV-dechloramination of swimming pool water on the formation of disinfection by-products: A lab-scale study.
}

\author{
Nicolas Cimetiere $^{\mathrm{ab}^{*}}$ and Joseph De Laat ${ }^{\mathrm{c}}$
}

${ }^{a}$ Ecole Nationale Supérieure de Chimie de Rennes, CNRS, UMR 6226, 11 Allée de Beaulieu, CS 50837, 35708 Rennes Cedex 7, France

${ }^{\mathrm{b}}$ Université européenne de Bretagne.

${ }^{\mathrm{c}}$ Institut de Chimie des Milieux et Matériaux de Poitiers (UMR CNRS 7285), Equipe Eau, Géochimie, Santé - Ecole Nationale Supérieure d'Ingénieurs de Poitiers, Université de Poitiers, 1 rue Marcel Doré, 86022 Poitiers Cedex, France

* Corresponding author, Nicolas CIMETIERE, nicolas.cimetiere@ensc-rennes.fr 


\begin{abstract}
UV dechloramination has become a very popular process for reducing the concentration of chloramines in public swimming pool water. As the effects of this process on the formation of disinfection byproducts (DBPs) remain a controversial issue, a bench-scale study has been undertaken to examine the impact of UV dechloramination on the formation of various DBPs. Four pool water samples were exposed to UV radiation at $254 \mathrm{~nm}$ in the presence of free chlorine $\left(\left[\mathrm{Cl}_{2}\right]_{0}=3 \mathrm{mg} \mathrm{L}{ }^{-1}\right)$ and then chlorinated in the dark for $24 \mathrm{~h}\left(\left[\mathrm{Cl}_{2}\right]_{0}=3 \mathrm{mg} \mathrm{L}^{-1}\right.$ ). High UV doses (up to $47 \mathrm{~kJ} \mathrm{~m}^{-2}$ ) were used to simulate cumulative UV doses received by real pool waters. The data showed that UV irradiation led to a $90 \%$ photodecay of free chlorine for UV doses ranging from 13 to $20 \mathrm{~kJ} \mathrm{~m}^{-2}$, to the formation of chlorate ion (0.05-0.11 mole of chlorate/mole of free chlorine decomposed) and to a significant increase in the chlorine demand of pool water during the post-chlorination step. UV exposure followed by post-chlorination did not significantly affect the formation of haloacetic acids, led to a small increase in the concentrations of adsorbable organic halogen (AOX) and of chloral hydrate and markedly increased the formation of trihalomethanes (chloroform, bromodichloromethane, chlorodibromomethane), dichloroacetonitrile, 1,1,1-trichloropropanone and chloropicrin.
\end{abstract}

Key-words: Chlorine demand, Trihalomethanes, Chloral hydrate, Haloacetonitriles, Haloacetic acids, 1,1-Dichloropropanone, 1,1,1-Trichloropropanone, Chloropicrin, Chlorate. 


\section{Abbreviations used for DBPs}

AOX: adsorbable organic halogen

BCAA: bromochloroacetic acid

BCAN: bromochloroacetonitrile

BDCM: bromodichloromethane

CDBM: chlorodibromomethane

$\mathrm{CH}$ : chloral hydrate

DBAN: dibromoacetonitrile

DBCAA: dibromochloroacetic acid

DBPs: disinfection by-products

DCAA: dichloroacetic acid

DCAN: dichloroacetonitrile

DCP: 1,1-dichloropropanone

HAAs: haloacetic acids

HANs: haloacetonitriles

MCAA: monochloroacetic acid

TBM: bromoform (tribromomethane)

TCAA: trichloroacetic acid

TCAN: trichloroacetonitrile

TCM: chloroform (trichloromethane)

TCNM: chloropicrin (trichloronitromethane)

TCP: 1,1,1-trichloropropanone

TOC: Total Organic Carbon

THMs: trihalomethanes 
TTHMs: total trihalomethanes

\section{Introduction}

Chlorine gas and sodium or calcium hypochlorite are the most common chemicals used for the disinfection of swimming pool water. According to the French regulations, the concentration of hypochlorous acid $(\mathrm{HOCl})$ in water and the $\mathrm{pH}$ must be kept between 0.4 and $1.4 \mathrm{mg} \mathrm{Cl}_{2} \mathrm{~L}^{-1}$ and 6.9 and 7.7, respectively [1]. Besides its disinfecting properties, chlorine reacts with contaminants introduced in water by the bathers to produce numerous undesirable disinfection by-products (DBPs), such as inorganic chloramines and organohalogenated by-products [2-8]

Among the inorganic chloramines, it is well-known that trichloramine $\left(\mathrm{NCl}_{3}\right)$ is very volatile and is a powerful irritant for eye and for the upper respiratory tract [9]. Exposure to trichloramine and to other volatile DBPs in swimming pool water can damage the lung epithelium of swimmers and may be involved in the asthma rise in children and lifeguards [10-12]. The concentration of trichloramine in the atmosphere of indoor swimming pool is not regulated. However, the French Institute of Occupational Health and Safety (INRS) has recommended a comfort limit value of $0.5 \mathrm{mg} \mathrm{NCl}_{3} \mathrm{~m}^{-3}$ [9]. The concentration of combined chlorine in water must not exceed $0.6 \mathrm{mg} \mathrm{Cl}_{2} \mathrm{~L}^{-1}$ in French public pools [1]. In order to meet this regulation, more than 500 French public pools have been equipped with a UV reactor during the last decade. Several UV systems equipped with Low Pressure (noted as LPUV) or with Medium Pressure (MPUV) lamps have been approved by the French Ministry of Health for dechloramination purposes [13]. In the pool water treatment chain, the UV reactor is inserted between the sand filter and the on-line injection point of the disinfectant. UV systems are usually operated at UV doses of $600 \mathrm{~J} \mathrm{~m}^{-2}$. In current applications, UV dechloramination is an efficient process for 
decreasing the concentration of combined chlorine because pool water is continuously recirculated through the UV reactor [13]. For a turnover period of pool water of about $1.5 \mathrm{~h}$, the cumulative dose of UV received by water is approximately equal to $10 \mathrm{~kJ} \mathrm{~m}^{-2}$ daily and therefore, the UV treatment will theoretically remove $90 \%$ of trichloramine after one day of treatment (Table S1 in the Supplementary Material). It must also be emphasized that UV dechloramination of swimming pool water will also decompose free chlorine because hypochlorous acid and hypochlorite ion absorb UV light [14]. In pure water, the photodecomposition rate of free chlorine at $254 \mathrm{~nm}$ is slower than the rates of photolysis of mono and dichloramine and is significantly faster in the presence of organic solutes [14]. The mechanisms of photodecomposition of chloramines and free chlorine are quite complex and are not well elucidated. Recent works showed that inorganic chloramines are decomposed by UV light into inorganic radicals and nitrite ions as intermediates and into ammonium, nitrite, nitrate and nitrous oxide as stable end-products [15-17]. Free chlorine photolysis leads to the formation of hydroxyl radicals and chlorine atoms as transient species which can further react with free chlorine to produce chloride ions and other oxychlorine species [15, 18-20].

Most of the reactions initiated by UV photolysis of chloramines and free chlorine are currently unknown but these reactions may affect the production of DBPs. To our knowledge, only four fullscale studies on the effects of UV dechloramination on the concentrations of DBPs in swimming pool have been published. The data obtained by Gérardin et al. [21] with reactors equipped with LPUV and MPUV lamps and by Cassan et al. [22] with a reactor equipped with MPUV lamps showed that UV dechloramination may increase the concentrations of trihalomethanes (THMs) in water by up to $250 \%$. On the other hand, no significant effect of UV irradiation on THM concentrations was observed by [23] (LPUV and MPUV lamps) and by Vrillet [24] (LPUV lamps). It is difficult to explain the discrepancy between the conclusions of these studies because many factors can affect the production of THMs such 
as the pool attendance, hydraulic residence time, UV dose, UV wavelength, free chlorine concentration and loss of volatile DBPs by stripping.

In order to better understand the effects of UV dechloramination on the formation of DBPs, laboratory experiments have been carried out in the present study under fully controlled conditions. Four pool water samples were exposed to UV light in a photoreactor equipped with a LPUV lamp in the presence of free chlorine ([Free chlorine $]_{0}=3 \mathrm{mg} \mathrm{L}^{-1}$ ) and at $\mathrm{UV}$ doses up to $47 \mathrm{~kJ} \mathrm{~m}^{-2}$ which correspond to typical cumulative UV doses received by real swimming pool waters for residence times ranging from 5 to 10 days. After exposure to UV light, pool water samples were post-chlorinated ([Free chlorine $]_{0}=$

$3 \mathrm{mg} \mathrm{L}^{-1}$ ). The effects of UV doses on the chlorine demands and on the formation of DBPs during the post-chlorination treatment have been investigated.

\section{Materials and Methods}

\subsection{Preparation of solutions}

All solutions were prepared from reagent-grade chemicals and purified water delivered by a Millipore system (Milli-RX75/Synergy 1985). The stock solution of sodium hypochlorite $\left(\approx 3 \mathrm{~g} \mathrm{Cl}_{2} \mathrm{~L}^{-1}\right)$ was prepared in purified water by dilution of a commercial solution of sodium hypochlorite (13\% Acros Organics) and addition of hydrochloric acid to adjust the $\mathrm{pH}$ to about 8.5-9.0 and then stored in the dark at $4^{\circ} \mathrm{C}$. Free chlorine concentration in the stock solution was determined just before use by iodometric titration.

Dilute solutions of free chlorine $\left(3 \mathrm{mg} \mathrm{Cl}_{2} \mathrm{~L}^{-1}\right)$ were prepared in phosphate buffered water ([TOC] $\leq$ $\left.0.1 \mathrm{mg} \mathrm{C} \mathrm{L}{ }^{-1}, \mathrm{pH}=7.4\right)$ and in tap water of the city of Poitiers $\left([\mathrm{TOC}]=0.4 \mathrm{mg} \mathrm{C} \mathrm{L}^{-1}, \mathrm{pH}=7.4\right)$ in order to compare the photodecomposition rates of free chlorine in various types of water.

\subsection{Pool water samples}


Four water samples were collected from three public indoor swimming pools between 8.00 am and $9.00 \mathrm{am}$, and used immediately upon arrival at the laboratory (Table 1). All the pools were treated by chlorine gas or sodium hypochlorite and none of them had a UV dechloramination system. Water samples were collected into a 10-L glass bottle. After collection, free and combined chlorine were not quenched by a reducing agent because the time elapsed between sampling and the arrival of the samples at the laboratory did not exceed $30 \mathrm{~min}$. The concentrations of free and total chlorine, total organic carbon (TOC) and nitrate, the $\mathrm{pH}$ and the UV absorbance at $254 \mathrm{~nm}$ of the four pool water samples have been reported in Table 1 .

\subsection{UV photoreactor}

Photolysis experiments were conducted by using a thermostated cylindrical batch reactor (Fig. S1 in the Supplementary Material). All experiments were performed at $25.0 \pm 0.5{ }^{\circ} \mathrm{C}$. The reactor was equipped with a LPUV lamp (Vilber Lourmat, $6 \mathrm{~W}$ ) emitting at $254 \mathrm{~nm}$. The UV lamp was turned-on during at least $20 \mathrm{~min}$ in a separated reactor in order to stabilize light output before introducing the lamp into the photoreactor. The volume of the aqueous solution in the reactor $(\mathrm{V})$ and the annular path length of the reactor (l) were equal to $4.00 \mathrm{~L}$ and $6.25 \mathrm{~cm}$, respectively. The photonic flux emitted by the UV lamp ( $\left.\mathrm{I}_{0}\right)$ was determined from photodecomposition rates of hydrogen peroxide as described previously by Nicole et al. [25]. The mean value of $\left(\mathrm{I}_{0}\right)$ was found to be equal to $(4.52 \pm 0.13) 10^{-6} \mathrm{E} \mathrm{s}^{-1}$ (Table S2) and corresponds to an irradiance of $19.5 \mathrm{~J} \mathrm{~s}^{-1} \mathrm{~m}^{-2}$. The UV dose and the wavelength of the photoreacteor were chosen to be representative of the dechloramination process using low-pressure UV lamp, commonly used in indoor swimming pool water.

\subsection{Experimental procedures}

Immediately upon the arrival of the pool water sample at the laboratory, a fraction of water was transferred into a 5000-mL volumetric flask. The concentration of free chlorine was then determined by 
the $\mathrm{N}, \mathrm{N}$-diethyl-p-phenylene diamine (DPD) colorimetric method and adjusted to $3 \mathrm{mg} \mathrm{Cl}_{2} \mathrm{~L}^{-1}\left(\left[\mathrm{Cl}_{2}\right]_{0}=\right.$ $3 \mathrm{mg} \mathrm{L}^{-1}$ ) by adding the appropriate volume of the stock solution of sodium hypochlorite under mixing. The chlorinated water sample was allowed to stand for 2 min under mixing in order to homogenise the solution. The concentrations of free and of combined chlorine were then determined again by the DPD colorimetric method.

In a first series of experiments, a volume of $4 \mathrm{~L}$ of chlorinated pool water sample was introduced in the photoreactor and exposed to UV light for reaction times ranging from 15 to $30 \mathrm{~min}$. At various irradiation times, free and total chlorine were determined by the DPD colorimetric method. In the case of a pool water sample (0410BLA), $10 \mathrm{~mL}$ samples of water were withdrawn from the UV reactor and transferred into $20 \mathrm{~mL}$ glass vials. The total sampled volume during the experiment does not exceed $200 \mathrm{~mL}$, thus the total volume of the reactor was considered constant. The concentration of free chlorine in each vial was adjusted to $3 \mathrm{mg} \mathrm{Cl}_{2} \mathrm{~L}^{-1}$. All vials were then sealed with Teflon-lined caps and stored in the dark at $25.0^{\circ} \mathrm{C}$ for $24 \mathrm{~h}$.

In a second series of experiments, a volume of $4 \mathrm{~L}$ of chlorinated pool water sample was introduced in the photoreactor and exposed to UV light for two consecutive periods of 20 min corresponding to UV doses of 23.5 and $47 \mathrm{~kJ} \mathrm{~m}^{-2}$ (Fig. 1). A volume of $250 \mathrm{~mL}$ of chlorinated water was also transferred (control) in a well sealed glass bottle leaving no head space and stored in darkness at $25.0^{\circ} \mathrm{C}$ for $24 \mathrm{~h}$. At the end of each period of UV exposure of $20 \mathrm{~min}$, the UV lamp was removed from the reactor (end of the first period) or turned off (end of the second period) and the remaining concentration of free chlorine in the UV reactor was immediately determined by the DPD colorimetric method and then adjusted to $3.0 \mathrm{mg} \mathrm{Cl}_{2} \mathrm{~L}^{-1}$. After $2 \mathrm{~min}$ of mixing in the UV reactor, $250 \mathrm{~mL}$ samples were withdrawn from the reactor. The two chlorinated samples of $250 \mathrm{~mL}$ were immediately transferred after sampling into well sealed glass bottles leaving no head space and stored in darkness at $25.0^{\circ} \mathrm{C}$ for $24 \mathrm{~h}$. 
After a post-chlorination time of $24 \mathrm{~h}$, the remaining concentrations of free chlorine in the vials or in the bottles were determined in order to determine the chlorine demands of the water samples during the post-chlorination step. The reactions of chlorine with organic and inorganic species were then stopped by adding $0.25 \mu \mathrm{L}$ of sodium thiosulfate $(1 \mathrm{M})$ and $0.5 \mu \mathrm{L}$ of $\mathrm{HCl}(2 \mathrm{M})$ per $\mathrm{mL}$ of water sample. The water samples present in the bottles were transferred in $125 \mathrm{~mL}$ amber bottles with no head space for storage in the dark at $4^{\circ} \mathrm{C}$ prior to DBP analyses. All the analyses of DBPs were made within a storage time of 5 days.

\subsection{Analytical methods}

\subsubsection{Analyses of organohalogenated by-products}

THMs were analyzed by the headspace technique combined with GC-MS. HANs, CH, DCP, TCP and TCNM were determined after liquid-liquid extraction by GC according to the USEPA Method 551.1. Haloacetic acids (HAAs) were determined according to the USEPA Method 552.2. The analytical protocols, the detection and quantification limits for each DBP have been reported in the Supplementary Material (Section S2.3).

The concentration of adsorbable organic halide (AOX) was determined according to the NF EN 1485 method by using a DX-20 Dohrmann AOX analyser. Analyses of AOX were made in duplicate and the relative standard deviation was $10 \%$.

\subsubsection{Other analytical methods}

Free chlorine concentration in the stock solution of sodium hypochlorite was determined by iodometry. Free and combined chlorine concentrations in swimming pools were determined by the DPD colorimetric with a portable spectrophotometer (Palintest 7500) using $10 \mathrm{~mL}$ of water samples and commercial DPD1 and DPD3 tablets.

The total organic carbon (TOC) was determined by a Shimadzu TOC analyzer (TOC-V $\mathrm{CSH}_{\text {). }}$ 
Chlorate was determined by ion chromatography (Dionex 4000) equipped with a column (AS-19), an electrochemical suppressor (ASR-4mm) and a conductimetric detector. Sodium hydroxide (10 $\mathrm{mM})$ was used as eluent (flow rate of $1 \mathrm{~mL} \mathrm{~min}^{-1}$ ). The injection volume was $500 \mu \mathrm{L}$ adopted. The detection and quantification limits were 30 and $100 \mu \mathrm{g} . \mathrm{L}^{-1}$, respectively.

\section{Results}

\subsection{Photodecomposition of free and combined chlorine}

Fig $2 \mathrm{a}$ shows that the rates of decomposition of free chlorine ([Free chlorine $]_{0}=3.0 \mathrm{mg} \mathrm{Cl}_{2} \mathrm{~L}^{-1}$ ) in phosphate buffered ultra-pure water $\left(\mathrm{pH}=7.4 ; \mathrm{TOC} \approx 0.1 \mathrm{mg} \mathrm{C} \mathrm{L}^{-1}\right)$ and in tap water of the city of Poitiers $\left(\mathrm{pH}=7.2\right.$; TOC $=0.40 \pm 0.05 \mathrm{mg} \mathrm{C} \mathrm{L}^{-1}$ ) were identical and first-order with respect to free chlorine (Fig. 2b). The apparent quantum yield of photodecomposition of free chlorine at $254 \mathrm{~nm}\left(\Phi_{\text {Free }}\right.$ chlorine) and at neutral $\mathrm{pH}$, determined from the first-order rate constant of photodecomposition of free chlorine $\left(\mathrm{k}_{\mathrm{app}}=1.0610^{-3} \mathrm{~s}^{-1}\right)$ and by using an apparent molar coefficient absorption of $62.5 \mathrm{M}^{-1} \mathrm{~cm}^{-1}$ for free chlorine at $\mathrm{pH}$ 7.2-7.4 was found to be equal to 1.06 (Section S.3.1). This value confirms the values determined by Feng et al. [14].

The data obtained with the two pool water samples ([Free chlorine $]_{0}=3 \mathrm{mg} \mathrm{L}^{-1}$; [Combined chlorine $]_{0}$ $\left.=0.7-0.8 \mathrm{mg} \mathrm{L}^{-1} ;[\mathrm{TOC}]=5.5-5.6 \mathrm{mg} \mathrm{L}^{-1} ; \mathrm{pH}=7.4-7.6\right)$ demonstrate that the decomposition rates of free chlorine were faster in pool water than in pure water (Fig. 2a) and did not follow a simple firstorder kinetics (Fig. 2b). These data are consistent with published works which showed that organic solutes can significantly promote the photodecomposition of free chlorine $[14,26]$. The data also indicate that free chlorine was almost completely removed after an irradiation time of 20 minutes corresponding to a UV dose of $23.5 \mathrm{~kJ} \mathrm{~m}^{-2}$ (Fig. 2a) and that the photodecomposition rates of combined chlorine in the pool water were equal or lower than the decomposition rates of free chlorine (Table 1). In full scale installations, the removal of chlorine species (as determined by DPD) between the inlet 
and the outlet of the UV reactor is usually low (a few \%) but the removals during one day of treatment or during the residence time of water in the pool is not negligible because the water is continuously recirculated in the UV reactor. The data concerning the decay of combined chlorine will not be discussed here because the DPD colorimetric method used in this work is not an appropriate analytical method for the quantification of the various inorganic and organic chloramines present in the pool water samples.

\subsection{Production of chlorate}

Ionic chromatography (IC) analyses showed that significant concentrations of chlorate ion (between 3.3 and $4 \mathrm{mg} \mathrm{L}^{-1}$ ) were found in swimming pools disinfected by sodium hypochlorite (Table 1). These data can be attributed to the presence of chlorate in the commercial solutions of $\mathrm{NaOCl}$ because chlorate is formed by hydrolysis of hypochlorite during the storage of $\mathrm{NaOCl}$ solutions. IC analyses also demonstrated that the photodecomposition of free chlorine in ultra-pure water (phosphate buffer: $\mathrm{pH}=$ 7.4; $[\text { Chlorine }]_{0}=55 \mu \mathrm{M}$ ) leads only to the production of chloride and chlorate ions as stable photoproducts. As shown in Fig. S4, the production of chlorate in ultra-pure water was approximately 0.09 mole of chlorate/mole of chlorine photodecomposed $\left(\approx 0.13 \mathrm{mg} \mathrm{ClO}_{3}{ }^{-}\right.$formed $/ \mathrm{mg} \mathrm{Cl}_{2} \mathrm{decomposed}$, in agreement with our previous works [27]. Yields ranging from 0.05 to $0.11 \mathrm{~mol} \mathrm{ClO}_{3}{ }^{-} / \mathrm{mol} \mathrm{Cl}_{2}$ decomposed were obtained from experiments performed with tap water and with pool water samples (Table 2). Chlorate ion is formed by secondary reactions involving primary photoproducts of $\mathrm{HOCl}$ and $\mathrm{ClO}^{-}$(hydroxyl radicals, chlorine and oxygen atoms, ...) but the reaction pathways have not yet been elucidated.

\subsection{Effect of the UV treatment on the chlorine demand during the postchlorination step}

Without UV pre-treatment, the chlorine demands of the four pool water samples during the postchlorination step ([Free chlorine $]_{0}=3 \mathrm{mg} \mathrm{Cl}_{2} \mathrm{~L}^{-1}$, Contact time $=24 \mathrm{~h}, 25^{\circ} \mathrm{C}$ ) ranged between 0.2 and 
$1.4 \mathrm{mg} \mathrm{Cl}_{2} \mathrm{~L}^{-1}$ or between 0.07 and $0.28 \mathrm{mg} \mathrm{Cl}_{2} / \mathrm{mg}$ TOC. The large difference in the chlorine consumptions can be attributed to the differences in the concentrations and in the nature of chlorineconsuming species that remain in pool water (organic solutes, nitrogen species, chloramines). It should be noted that a chlorine demand of $0.2 \mathrm{mg} \mathrm{L}^{-1}$ represents an abnormally low value.

Data obtained with the pool water sample 0410BLA (Fig. 3a) showed that UV irradiation led to an increase in the chlorine demand of pool water during the post-chlorination step. The chlorine demand increased from $1.45 \mathrm{mg} \mathrm{Cl}_{2} \mathrm{~L}^{-1}\left(0.26 \mathrm{mg} \mathrm{Cl}_{2} / \mathrm{mg}\right.$ TOC) for the control sample (UV dose $=0 \mathrm{~kJ} \mathrm{~m}^{-2}$ ) to approximately $2.5-2.7 \mathrm{mg} \mathrm{Cl} \mathrm{L}^{-1}\left(0.45-0.50 \mathrm{mg} \mathrm{Cl} / \mathrm{mg}\right.$ TOC) for UV doses of 23-35 $\mathrm{kJ} \mathrm{m}^{-2}$ (irradiation time $=20-30 \mathrm{~min}$ ). It should be noted that the amounts of chlorine decomposed during the UV treatment (Fig. 2a, $3 \mathrm{mg} \mathrm{Cl}_{2} \mathrm{~L}^{-1}$ after $20 \mathrm{~min}$ of UV irradiation) have not been taken into account in the chlorine demand and that a residual of free chlorine was present in all the pool water samples after a post-chlorination time of $24 \mathrm{~h}$.

The increase in the chlorine demand after UV treatment has also been confirmed by experiments performed with the four pool water samples at UV doses of 23.5 and $47 \mathrm{~kJ} \mathrm{~m}^{-2}$ according to the experimental conditions described in Fig. 1. The percentages of increase in the chlorine demand were approximately equal to 50-70\% for 0410BLA; 150- $220 \%$ for 0427GAN and 0428BEL and about 520-620\% for 0421GAN (Table 2 and Fig. 4a). The latter value is very high because of the abnormal low value of the chlorine demand of the control sample $\left(0.2 \mathrm{mg} \mathrm{Cl}_{2} \mathrm{~L}^{-1}\right)$. These data demonstrate that UV dechloramination of swimming pool waters leads to the formation of by-products which are more reactive with chlorine than the parent compounds, most probably via secondary reactions involving photo-products generated from the photolysis of chloramines and free chlorine. Our data also demonstrate that UV dechloramination of swimming pool water would increase the chlorine consumption by two main ways: direct photolysis reactions of free chlorine in the UV chamber and increase in the chlorine demand of the pool water. 


\subsection{Effect of UV dechloramination on the post-chlorination DBP formation}

For the pool water sample 0410BLA, Fig. 3 presents the effects of UV doses (in the range 0-35 kJ m${ }^{-2}$ ) on the concentrations of chloroform (TCM) (Fig.3a), TCP and TCNM (Fig.3b) measured after the postchlorination treatment. For the four water samples, Table 2 and Fig.4b-4d) show the concentrations of DBPs obtained from experiments which have been carried out under the conditions described in Fig. 1 (UV doses : 0, 23.5 and $47 \mathrm{~kJ} \mathrm{~m}^{-2}$ ). It must be emphasized that UV exposure has been performed in the presence of free chlorine and that the total amounts of free chlorine decomposed in the UV reactor are equal to 3 and $6 \mathrm{mg} \mathrm{L}^{-1}$ for UV doses of 23.5 and $47 \mathrm{~kJ} \mathrm{~m}^{-2}$, respectively. The effects of UV treatment will be discussed below by examining the effects of UV doses on the concentrations of DBPs or on the $[\mathrm{C}]_{23.5}:[\mathrm{C}]_{0}$ or $[\mathrm{C}]_{47}:[\mathrm{C}]_{0}$ ratios, where $[\mathrm{C}]_{0}$ represents the concentration of a DBP or of a group of DBPs in the control sample (non-irradiated sample, UV dose $=0 \mathrm{~kJ} \mathrm{~m}^{-2}$ ) and $[\mathrm{C}]_{23.5}$ and $[\mathrm{C}]_{47}$, the concentrations in samples which have been exposed to UV doses of 23.5 and $47 \mathrm{~kJ} \mathrm{~m}^{-2}$, respectively.

\subsubsection{Effect of UV dechloramination on the formation of AOX}

Concentrations of AOX in the four control water samples (UV dose: $0 \mathrm{~kJ} \mathrm{~m}^{-2}$ ) determined after the post-chlorination step ranged from 510 to $1110 \mu \mathrm{g} \mathrm{L}^{-1}$ (Table 2) and the highest concentrations of AOX were found in pool waters having the highest TOC content. The concentration levels of AOX obtained with the four studied samples were consistent with published values (Brunet et al., 2010). As it will be detailed later in the manuscript, the monitored BDPs (THMs HANs, CH, DCP, TCP, TCNM and HAAs) represent approximatively $50 \%$ of the AOX . This is consistent with previously published data where the unidentified AOX represents more than $60 \%$ of the AOX in drinking water [28].

Data in Table 2 show that the UV treatment $\left(\mathrm{UV}\right.$ dose $\left.=47 \mathrm{~kJ} \mathrm{~m}^{-2}\right)$ in the presence of free chlorine increased the post-chlorination AOX formation by approximately $20 \%$ (Table 2; $1.13<$ $\left.[\mathrm{AOX}]_{47}:[\mathrm{AOX}]_{0}<1.29\right)$. AOX analyses have not been done for the UV dose of $23.5 \mathrm{~kJ} \mathrm{~m}^{-2}$. The 
increase in the AOX formation after UV exposure is also consistent with the data obtained for the chlorine demand because an increase in the AOX formation can be expected when the chlorine demand increases.

\subsubsection{Effect on the formation of THMs}

GC/MS analyses of pool water samples showed that the total concentration of THMs (TTHMs) ranged from 29 to $69 \mu \mathrm{g} \mathrm{L}^{-1}$ and accounted for $5.5 \%$ ( $\mathrm{sd}=0.5,4$ values) of the AOX concentration of the studied waters (Table 2). TCM was the dominant THM and represented 85-90\% of the TTHMs. The contribution of bromodichoromethane (BDCM) and dibromochloromethane (DBCM) to the TTHMs were approximately 10 and $2.5 \%$, respectively. Concentrations levels of bromoform (TBM) were very

low (0.4-1 $\left.\mu \mathrm{g} \mathrm{L}^{-1}\right)$. It should also be noted that a comparison of THM concentrations determined before and after post-chlorination of the control samples indicates that the post-chlorination treatment did not increase the concentrations of THMs by more than $10 \%$ (data not shown).

Data presented in Fig. 3a show that UV irradiation of the pool water 0410BLA in the presence of free chlorine increased the TCM formation during the post-chlorination step by approximately $80 \%$. Interestingly, the post-chlorination TCM formation did not significantly increase for pre-irradiation doses higher than $12 \mathrm{~kJ} \mathrm{~m}^{-2}$, which corresponds to an irradiation time of $10 \mathrm{~min}$ and to a $75 \%$ decomposition of free chlorine in the UV reactor (Fig. 2a). These data suggest that the effect of UV radiation on the formation of TCM might be mainly attributed to reactions between the organic solutes present in pool water and the transient species generated from the photolysis of free chlorine and chloramines.

These data were confirmed by the experiments carried out with the four water samples under the conditions described in Fig. 1. As shown the data reported in Table 2 and in Fig. 4b, UV doses of 23.5 ad $47 \mathrm{~kJ} \mathrm{~m}^{-2}$ increased the post-chlorination chloroform formation by approximately $90 \%$ (mean value for $\left.[\mathrm{TCM}]_{23.5}:[\mathrm{TCM}]_{0}=1.94, \mathrm{sd}=0.40\right)$ and $150 \%\left(\right.$ mean value for $[\mathrm{TCM}]_{47}:[\mathrm{TCM}]_{0}=2.53, \mathrm{sd}=$ 
0.75), respectively. As depicted in Fig. 4b, the mean increase in the chloroform formation was higher for the first irradiation dose of $23.5 \mathrm{~kJ} \mathrm{~m}^{-2}$ (mean value for $[\mathrm{TCM}]_{23.5} /[\mathrm{TCM}]_{0}=1.94$, $\mathrm{sd}=0.40$ ) than for the second irradiation of $23.5 \mathrm{~kJ} \mathrm{~m}^{-2}$ (mean value for $[\mathrm{TCM}]_{47}:[\mathrm{TCM}]_{23.5}=1.29$, sd $=0.11$ ). Since TCM represents the dominant THM ( $\approx 85 \%$ of TTHMs), UV treatment also increased the postchlorination formation of TTHMs by $84 \%$ and $165 \%$ for UV doses of 23.5 and $47 \mathrm{~kJ} \mathrm{~m}^{-2}$, respectively $\left(\right.$ mean value for $\left.[\text { TTHMs }]_{23.5}:[\text { TTHMs }]_{0}=2.04, \mathrm{sd}=0.44 ;[\text { TTHMs }]_{47} /[\text { TTHMs }]_{0}=2.65, \mathrm{sd}=0.76\right)$.

UV treatment also markedly increased the concentrations of BDCM $\left([\mathrm{BDCM}]_{23.5}:[\mathrm{BDCM}]_{0}=3.21\right.$, sd $=0.82 ;\left([\mathrm{BDCM}]_{47}:[\mathrm{BDCM}]_{0}=4.17, \mathrm{sd}=1.22\right)$ and DBCM $\left([\mathrm{DBCM}]_{23.5}:[\mathrm{DBCM}]_{0}=2.16, \mathrm{sd}=0.46\right.$; $\left([\mathrm{DBCM}]_{47}:[\mathrm{DBCM}]_{0}=2.29, \mathrm{sd}=0.34\right)$. The increases in the concentrations of BDCM and DBCM were higher that than those obtained for TCM but the concentrations levels of BDCM and DBCM are much lower that the concentrations of TCM. On the contrary, the UV treatment reduced the formation of TBM. These data can be explained by the fact that brominated THMs can be photodecomposed by UV light emitted by LPUV lamps (molar absorption coefficient ( $\varepsilon$ ) of TCM, BDCM, DBCM and TBM at $254 \mathrm{~nm}:<0.1,42.3,228.5$ and $519 \mathrm{M}^{-1} \mathrm{~cm}^{-1}$, respectively; quantum yield $(\Phi)$ at $254 \mathrm{~nm}=0.43$ for BDCM, DBCM and TBM, [29]). By using the values of $\varepsilon$ and $\Phi$, calculations indicate that the percent removals of BDCM, DBCM and TBM at a UV dose of $23.5 \mathrm{~kJ} \mathrm{~m}^{-2}$ should be roughly equal to 30,85 and $98 \%$, respectively. These calculations can be used to explain the decrease in the concentration of TBM in UV treated waters. In the case of BDCM, DBCM, the observed increase in the concentrations of these two THMs in post-chlorinated water suggest that the amounts of BDCM and DBCM formed during post-chlorination were higher than the amounts of BDCM and DBCM which were photodecomposed in the UV reactor. In their full-scale study of the effect of UV-dechloramination on the formation of THM, Cassan et al. [22] observed an increase in the concentration of TCM and of BDCM and a decrease in the concentrations of DBCM and TBM in water when the MPUV lamp was 
turned on. As compared to LPUV lamps, MPUV lamps are more efficient for the photodegradation of brominated THMs because these DBPs have a broad absorption band with a maximum at $220 \mathrm{~nm}$ [29]. It should also be noted that the contribution of TTHMs to AOX increased from $5.5 \%$ (sd $=0.5,4$ values) to $\approx 12.2 \%$ ( $\mathrm{sd}=4.3,4$ values) when the UV dose increased from 0 to $47 \mathrm{~kJ} \mathrm{~m}^{-2}$.

\subsubsection{Effect on the formation of HAAs}

For the control samples (UV dose $=0 \mathrm{~kJ} \mathrm{~m}^{-2}$ ), the total concentration of HAAs including the five HAAs measured in the present work (monochloroacetic acid (MCAA); dichloroacetic (DCAA); trichloroacetic acid (TCAA); bromochloroacetic acid (BCAA) and dibromoacetic acid (DBAA)) ranged from 208 to $530 \mu \mathrm{g} \mathrm{L}^{-1}$ and represented $24.6 \%(\mathrm{sd}=2.3,4$ values) of the AOX (Table 2). Among the HAAs, DCAA $\left(117-361 \mu \mathrm{g} \mathrm{L} \mathrm{L}^{-1} ; 58 \%\right.$ of total HAAs) and TCAA (74-183 $\mu \mathrm{g} \mathrm{L}{ }^{-1}, 37 \%$ of total HAAs) were the two dominant HAAs and accounted for 93.5-96 \% of the total HAAs. MCAA and BCAA were detected at concentration levels ranging from 6 to $15 \mu \mathrm{g} \mathrm{L}^{-1}$ and the concentrations of DBAA were below the quantification limit of $1 \mu \mathrm{g} \mathrm{L} \mathrm{L}^{-1}$.

As shown the data in Table 2, the UV dechloramination pre-treatment of the four pool water samples did not affect the speciation of HAAs and the total concentration of HAAs in post-chlorinated samples because the variations in the concentrations of HAAs were within the analytical errors $\left([\text { THAAs }]_{23.5}:[\text { THAAs }]_{0}=1.04, \mathrm{sd}=0.04 ;[\text { THAAs }]_{47}:[\text { THAAs }]_{0}=0.99, \mathrm{sd}=0.13\right)$.

\subsubsection{Effect on the formation of chloral hydrate $(\mathrm{CH})$}

In agreement with published works $[6,30], \mathrm{CH}$ was one of the most abundant $\mathrm{DBP}$ in swimming pool waters. Concentration levels of $\mathrm{CH}$ in control samples varied from 100 to $380 \mu \mathrm{g} \mathrm{L}^{-1}$ and represented approximately $17.9 \%$ (sd 5.5; 4 values) of the AOX (Table 2). Data in Table 2 and in Fig. 4c show that the UV dechloramination treatment leads to a relative small increase in the post-chlorination formation of $\mathrm{CH}\left([\mathrm{CH}]_{23.5}:[\mathrm{CH}]_{0}=1.18, \mathrm{sd}=0.16 ;[\mathrm{CH}]_{47}:[\mathrm{CH}]_{0}=1.27, \mathrm{sd}=0.22\right)$. 


\subsubsection{Effect on the formation of haloacetonitriles (HANs)}

With regards to HANs, analyses of dichloroacetonitrile (DCAN), trichloroacetonitrile (TCAN), bromochloroacetonitrile (BCAN) and dibromoacetonitrile (DBAN) in control samples showed that the concentration levels of DCAN and of CBAN ranged from 2.8 to $18.6 \mu \mathrm{g} \mathrm{L}^{-1}$ and from 0.8 to $3.8 \mu \mathrm{g} \mathrm{L}^{-1}$, respectively (Table 2). DCAN accounted for $75 \%$ to total HANs ( $\mathrm{sd}=7.5 ; 4$ values) and BCAN for 21 $\%(\mathrm{sd}=4.2 ; 4$ values). TCAN and DBAN were not detected in all samples and their concentrations were always less than $1 \mu \mathrm{g} \mathrm{L}{ }^{-1}$. When the water samples were exposed to $\mathrm{UV}$ radiation, significant increases in the concentrations of DCAN $\left([\mathrm{DCAN}]_{23.5}:[\mathrm{DCAN}]_{0}=2.19, \quad\right.$ sd $=0.56$; $[\text { DCAN }]_{47}:[\mathrm{DCAN}]_{0}=2.73$, sd $\left.=1.05\right)$ and of $\left([\mathrm{BCAN}]_{23.5}:[\mathrm{BCAN}]_{0}=2.28\right.$, sd $=0.67$; $[\mathrm{BCAN}]_{47}:[\mathrm{BCAN}]_{0}=2.66, \mathrm{sd}=0.80$ ) were observed after the post-chlorination step (Table 2 and Fig. $4 d)$.

\subsubsection{Effects on the formation of 1,1-dichloropropanone (DCP) and 1,1,1-trichloropropanone (TCP)}

DCP was detected in only one control sample at a concentration of $3.2 \mu \mathrm{g} \mathrm{L}^{-1}$ and in post-chlorinated water samples at concentrations less than $0.3 \mu \mathrm{g} \mathrm{L}^{-1}$ (Table 2). Data obtained for TCP demonstrate that the concentration of TCP in the four control samples ranged from 0 to $11.4 \mu \mathrm{g} \mathrm{L} \mathrm{L}^{-1}$ and that UV treatment significantly increased the concentrations of TCP in post-chlorinated samples (Table 2 Fig. $4 d)$.

\subsubsection{Effect on the formation of chloropicrin (TCNM)}

TCNM was detected in two control water samples at concentrations of 0.4 and $1 \mu \mathrm{g} \mathrm{L} \mathrm{L}^{-1}$ (Table 2) which are of the same order of magnitude than values reported in literature [2]. As shown the data presented in Figs $3 \mathrm{~b}$ and $4 \mathrm{~d}$ and in Table 2, UV dechloramination / post-chlorination sequence significantly increased the TCNM formation to concentration levels ranging from 1.6 to $3.8 \mu \mathrm{g} \mathrm{L}^{-1}$. For the two 
control water samples which did not contain TCNM (detection limit: $0.1 \mu \mathrm{g} \mathrm{L}^{-1}$ ), the concentrations of TCNM were approximately equal to 1.6-2.2 $\mu \mathrm{g} \mathrm{L}^{-1}$. For the two other pool waters, TCNM concentrations increased by up to 300-350 \% after the UV dechloramination/post-chlorination treatment $\left([\mathrm{TCNM}]_{23.5}:[\mathrm{TCNM}]_{0}=8.60, \mathrm{sd}=6.61 ;[\mathrm{TCNM}]_{47} /[\mathrm{TCNM}]_{0}=9.52, \mathrm{sd}=9.09,3\right.$ values $)$. An increase in the formation of TCNM has also been previously observed with drinking water samples when chlorination followed a UV treatment with MPUV lamps in the absence of free and combined chlorine [31].

TCNM is a by-product resulting of the chlorination of nitro-organic compounds. However, the identity of TCNM precursors in drinking waters and in swimming pool waters is unknown. It has also been shown that pre-ozonation of natural water, drinking water or treated wastewater prior to chlorination can substantially increase the formation of TCNM [32-34] and of other halonitromethanes [35, 36] probably because ozonation facilitates the oxidation of nitrogen compounds into nitro-organic compounds. MPUV irradiation of drinking water prior to chlorination was also found to increase the TCNM formation whereas LPUV irradiation had no effect on TCNM formation [31]. Precursors of TCNM can also be formed from non-nitrogenous organic solutes by dark nitration reactions occurring during the oxidation of nitrite by various oxidants (chlorine, ozone, chlorine dioxide, monochloramine) in the presence of phenols [37] or by photonitration reactions occurring during UV irradiation of phenols in the presence of nitrate [38].

In the present work, UV irradiation of pool water samples has been performed with a LPUV lamp, high UV dose (up to $47 \mathrm{~kJ} \mathrm{~m}^{-2}$ ) and in the presence of free chlorine ([Free $\left.\mathrm{Cl}_{2}\right]_{0}=3 \mathrm{mg} \mathrm{L} \mathrm{L}^{-1}$ ), combined chlorine $\left(\left[\mathrm{Combined} \mathrm{Cl}_{2}\right]_{0}=0.3-0.8 \mathrm{mg} \mathrm{L}^{-1}\right)$ and nitrate $(\approx 0.5-0.8 \mathrm{mM})$. The substantial increase in the formation of TCNM which has been observed after UV dechloramination and post-chlorination treatments can be attributed to various reactions which have already been proposed to explain the 
effects of water treatment processes (ozonation, UV disinfection) or of nitrite ion on the formation of TCNM. Highly reactive hydroxyl radicals formed during photolysis of free chlorine [15, 20], nitrite and nitrate ions [39] can oxidise nitrogenous organic solutes into more reactive TCNM precursors. Nitrite ion formed by photolysis at $254 \mathrm{~nm}$ of monochloramine [16, 17] and nitrate [40] may also lead to the formation of nitro-compounds during its oxidation by free chlorine and other oxidizing species in the presence of organic solutes. In addition, photonitration reactions involving transient species formed during photolysis of nitrate, nitrite and chloramines may also be a source of TCNM precursors.

\section{Conclusions}

This laboratory-scale study demonstrates that UV dechloramination of swimming pool water by LPUV lamps and at UV doses similar to those usually applied for real pool water (cumulative UV doses up to $50 \mathrm{~kJ} \mathrm{~m}^{-2}$ and presence of free chlorine) significantly increases the chlorine demand of pool waters and the formation of some DBPs (more particularly TCM, BDCM, CDBM, DCAN, TCP and TCNM) during the post-chlorination step. All these data will be confirmed by our full-scale studies (not presented here) because similar trends were obtained for the effects of UV dechloramination by MP UV lamps on the chlorine consumption and on the formation of DBPs.

This study supports that UV dechloramination of swimming pool water significantly changes the formation potentials of DBPs because UV treatment initiate numerous oxidation, hydroxylation and nitration reactions involving transient species $\left(\mathrm{Cl}^{\circ}, \mathrm{HO}^{\circ}\right.$, organic radicals...) formed from the photolysis of free chlorine species, chloramines and nitrate ions. As the precursors of the various DBPs in swimming pool water are not well known and because of the complexity of reaction pathways, additional research is needed in order to elucidate most of the reaction mechanisms, and in particular, the reaction pathways leading to the increase in the formation of THMs and of TCNM. 
Acknowledgments: French Agency for Food, Environmental and Occupational Health \& Safety (ANSES, Paris) for funding this study.

\section{Appendix. Supplementary material}

Supplementary data related to this article can be found online at doi: 


\section{References}

[1] J.O., Arrêté du 7 avril 1981 fixant les dispositions techniques applicables aux piscines modifié par l'arrêté du 28 septembre 1989 et l'arrêté du 18 janvier 2002., Journal Officiel de la République Française, (1981).

[2] WHO, Guidelines for safe recreational water environments. Volume 2: Swimming pools and similar environments., World Health Organization. (2006).

[3] S.J. Judd, G. Bullock, The fate of chlorine and organic materials in swimming pools, Chemosphere, $51(2003) 869-879$.

[4] C. Zwiener, S.D. Richardson, D.M. De Marini, T. Grummt, T. Glauner, F.H. Frimmel, Drowning in Disinfection Byproducts? Assessing Swimming Pool Water, Environmental Science \& Technology, 41 (2007) 363-372.

[5] W.A. Weaver, J. Li, Y. Wen, J. Johnston, M.R. Blatchley, E.R. Blatchley III, Volatile disinfection by-product analysis from chlorinated indoor swimming pools, Water Research, 43 (2009) 3308-3318.

[6] R. Brunet, F. Berne, J. De Laat, Disinfection by-products in chlorinated swimming pool waters, L'Eau, L'Industrie, Les Nuisances, 333 (2010) 84-88.

[7] J. Lee, M.-J. Jun, M.-H. Lee, M.-H. Lee, S.-W. Eom, K.-D. Zoh, Production of various disinfection byproducts in indoor swimming pool waters treated with different disinfection methods, International Journal of Hygiene and Environmental Health, 213 (2010) 465-474.

[8] S.D. Richardson, D.M. DeMarini, M. Kogevinas, P. Fernandez, E. Marco, C. Lourencetti, C. Ballesté, D. Heederik, K. Meliefste, A.B. McKague, R. Marcos, L. Font-Ribera, J.O. Grimalt, C.M. Villanueva, What's in the pool? A comprehensive identification of disinfection by-products and assessment of mutagenicity of chlorinated and brominated swimming pool water., Environmental Health Perspectives, 118 (2010). 
[9] M. Hery, G. Hecht, J.M. Gerber, J.C. Gendre, G. Hubert, J. Rebuffaud, Exposure to chloramines in the atmosphere of indoor swimming pools, The Annals of Occupational Hygiene, 39 (1995) 427-439. [10] A. Bernard, S. Carbonnelle, O. Michel, S. Higuet, C. De Burbure, J. Buchet, C. Hermans, X. Dumont, I. Doyle, Lung hyperpermeability and asthma prevalence in schoolchildren: unexpected associations with the attendance at indoor chlorinated swimming pools., Occupational and Environmental Medicine, 60 (2003) 385-394.

[11] J.H. Jacobs, S. Spaan, G.B.G.J. van Rooy, C. Meliefste, V.A.C. Zaat, J.M. Rooyackers, D. Heederik, Exposure to trichloramine and respiratory symptoms in indoor swimming pool workers, European Respiratory Journal, 29 (2007) 690-698.

[12] C.P. Weisel, S.D. Richardson, B. Nemery, G. Aggazzotti, E. Baraldi, E.R. Blatchley III, B.C. Blount, K.H. Carlsen, P.A. Eggleston, F.H. Frimmel, M. Goodman, G. Gordon, S.A. Grinshpun, D.J.J. Heederik, M. Kogevinas, J.S. aKind, M.J. Nieuwenhuijsen, F.C. Piper, S.A. Sattar, Childhood asthma and environmental exposures at swimming pools: state of the science and research recommendations, Environmental Health Perspectives, 117 (2009) 500-507.

[13] J. De Laat, F. Berne, Theoretical and practical aspects of the dechloramination of swimming pool water by UV irradiation, European Journal of Water Quality, 40 (2009) 129-149.

[14] Y. Feng, D.W. Smith, J.R. Bolton, Photolysis of aqueous free chlorine species (HOCl and OCl-) with $254 \mathrm{~nm}$ ultraviolet light, Journal of Environmental Engineering and Science, 6 (2007) 277-284.

[15] M.J. Watts, K.G. Linden, Chlorine photolysis and subsequent OH radical production during UV treatment of chlorinated water, Water Research, 41 (2007) 2871-2878.

[16] J. Li, E.R. Blatchley III, UV Photodegradation of Inorganic Chloramines, Environmental Science \& Technology, 43 (2009) 60-65. 
[17] J. De Laat, N. Boudiaf, F. Dossier-Berne, Effect of dissolved oxygen on the photodecomposition of monochloramine and dichloramine in aqueous solution by UV irradiation at $253.7 \mathrm{~nm}$, Water Research, 44 (2010) 3261-3269.

[18] G.V. Buxton, M.S. Subhani, Radiation chemistry and photochemistry of oxychlorine ions. Part 2.Photodecomposition of aqueous solutions of hypochlorite ions, Journal of the Chemical Society, Faraday Transactions 1: Physical Chemistry in Condensed Phases, 68 (1972) 958-969.

[19] L.H. Nowell, J. Hoigné, Photolysis of aqueous chlorine at sunlight and ultraviolet wavelengthsII. Hydroxyl radical production, Water Research, 26 (1992) 599-605.

[20] J. Jin, M.G. El-Din, J.R. Bolton, Assessment of the UV/Chlorine process as an advanced oxidation process, Water Research, 45 (2011) 1890-1896.

[21] F. Gérardin, G. Hecht, G. Hubert-Pelle, I. Subra, Traitement UV: Suivi des concentrations en chloroforme et en trichlorure d'azote dans les eaux de baignade d'un centre aquatique, INRS-HST, ND 2237, 201 (2005) 19-30.

[22] D. Cassan, B. Mercier, F. Castex, A. Rambaud, Effects of medium-pressure UV lamps radiation on water quality in a chlorinated indoor swimming pool, Chemosphere, 62 (2006) 1507-1513.

[23] G.L. Kristensen, M.M. Klausen, H.R. Andersen, L. Erdinger, F. Lauritsen, E. Arvin, H.J. Albrechtsen, Full scale test of UV-based water treatment technologies at Gladsaxe Sport Centre - with and without advanced oxidation mechanisms., , in: Swimming Pool \& Spa International Conference, London, 2009.

[24] G. Vrillet, Use of UV low pressure amalgam lamps for dechloramination of public swimming pool, L'Eau, l'Industrie, les Nuisances 333 (2010).

[25] I. Nicole, J. De Laat, M. Dore, J.P. Duguet, C. Bonnel, Utilisation du rayonnement ultraviolet dans le traitement des eaux: mesure du flux photonique par actinometrie chimique au peroxyde d'hydrogene, Water Research, 24 (1990) 157-168. 
[26] B. Ormeci, J.J. Ducoste, K.J. Linden, UV disinfection of chlorinated water: impact on chlorine concentration and UV delivery, Journal Water Supply: Research. and Technology - Aqua, 54 (2005) 189-199.

[27] N. Karpel Vel Leitner, J. De Laat, M. Dore, Photodecomposition du bioxyde de chlore et des ions chlorite par irradiation U.V. en milieu aqueux — partie I. Sous-produits de reaction, Water Research, 26 (1992) 1655-1664.

[28] S.D. Richardson, J.E. Simmons, G. Rice, Peer Reviewed: Disinfection Byproducts: The Next Generation, Environmental Science \& Technology, 36 (2002) 198A-205A.

[29] I. Nicole, J. De Laat, M. Dore, J.P. Duguet, H. Suty, Etude de la degradation des trihalo-methanes en milieu aqueux dilue par irradiation UV - determination du rendement quantique de photolyse a 253,7 nm 1, Environmental Technology, 12 (1991) 21-31.

[30] M. Clemens, H.F. Schöler, Halogenated organic compounds in swimming pool water, Zentralblatt für Hygiene und Umweltmedizin = International Journal of Hygiene and Environmental Medicine, 193 (1992) 91-98.

[31] D.A. Reckhow, K.G. Linden, J. Kim, H. Shemer, G. Makdissy, Effect of UV treatment on DBP formation, J. American Water Works Association, 102 (2010).

[32] N. Merlet, H. Thibaud, M. Dore, Chloropicrin formation during oxidative treatments in the preparation of drinking water, Science of The Total Environment, 47 (1985) 223-228.

[33] J. Hoigné, H. Bader, The formation of trichloronitromethane (chloropicrin) and chloroform in a combined ozonation/chlorination treatment of drinking water, Water Research, 22 (1988) 313-319.

[34] P.-C. Chiang, E.E. Chang, C.-C. Chuang, C.-H. Liang, C.-P. Huang, Evaluating and elucidating the formation of nitrogen-contained disinfection by-products during pre-ozonation and chlorination, Chemosphere, 80 (2010) 327-333. 
[35] H. Song, J.W. Addison, J. Hu, T. Karanfil, Halonitromethanes formation in wastewater treatment plant effluents, Chemosphere, 79 (2010) 174-179.

[36] J. Hu, H. Song, J.W. Addison, T. Karanfil, Halonitromethane formation potentials in drinking waters, Water Research, 44 (2010) 105-114.

[37] H. Thibaut, J. De Laat, N. Merlet, M. Doré, Chloropicrin formation in aqueous solution: effect of nitrites on precursor formation during the oxidation of organic compounds, Water Research, 21 (1987) 813-821.

[38] J. Dzengel, J. Theurich, D.W. Bahnemann, Formation of Nitroaromatic Compounds in Advanced Oxidation Processes: Photolysis versus Photocatalysis, Environmental Science \& Technology, 33 (1999) 294-300.

[39] J. Mack, J.R. Bolton, Photochemistry of nitrite and nitrate in aqueous solution: a review, Journal of Photochemistry and Photobiology A: Chemistry, 128 (1999) 1-13.

[40] C.M. Sharpless, K.G. Linden, UV Photolysis of Nitrate: Effects of Natural Organic Matter and Dissolved Inorganic Carbon and Implications for UV Water Disinfection, Environmental Science \& Technology, 35 (2001) 2949-2955. 


\section{List of Tables}

Table 1 - Composition of the four swimming pool water samples and experimental data obtained for the photodecomposition rates of free and combined chlorine and for the molar yields of chlorate in swimming pool waters.

Table 2 - Effects of UV treatment (UV dose $=0,23.5$ or $47 \mathrm{~kJ} \mathrm{~m}^{-2}$ ) on the chlorine demands and on the productions of DBPs during the postchlorination step (Experimental conditions: see Fig. 1). 
Table 1 - Composition of the four swimming pool water samples and experimental data obtained for the photodecomposition rates of free and combined chlorine and for the molar yields of chlorate in swimming pool waters.

\begin{tabular}{|c|c|c|c|c|c|c|}
\hline Swimming water sample & $\begin{array}{l}\text { Pure } \\
\text { water }\end{array}$ & $\begin{array}{l}\text { Tap water } \\
\text { Poitiers }\end{array}$ & 0410BLA & 0421GAN & 0427GAN & 0428BEL \\
\hline Sampling date & & $\begin{array}{l}\text { April 10, } \\
2010\end{array}$ & $\begin{array}{l}\text { April 10, } \\
2010\end{array}$ & $\begin{array}{l}\text { April 21, } \\
2010\end{array}$ & $\begin{array}{l}\text { April 27, } \\
2010\end{array}$ & $\begin{array}{c}\text { April 28, } \\
2010\end{array}$ \\
\hline Disinfectant used & & $\mathrm{Cl}_{2}$ gas & $\mathrm{NaOCl}$ & $\mathrm{Cl}_{2}$ gas & $\mathrm{Cl}_{2}$ gas & $\mathrm{NaOCl}$ \\
\hline $\mathrm{UV}$ transmittance at $254 \mathrm{~nm}\left(\mathrm{~cm}^{-1}\right.$ & & & 98.6 & 98.7 & 98.8 & 98.7 \\
\hline Alkalinity $\left(\mathrm{mg} \mathrm{CaCO}_{3} \mathrm{~L}^{-1}\right)$ & & & 103 & 66 & 67 & 95 \\
\hline Nitrate $\left(\mathrm{mg} \mathrm{L}^{-1}\right)$ & & & 46.3 & 38.0 & 34.2 & 39.9 \\
\hline Chlorate $\left(\mathrm{mg} \mathrm{L}^{-1}\right)$ & 0 & $<0.1$ & 3.96 & $<0.1$ & $<0.1$ & 3.30 \\
\hline$\left[\right.$ Free $\left.\mathrm{Cl}_{2}\right] /\left[\right.$ Total $\left.\mathrm{Cl}_{2}\right]\left(\mathrm{mg} \mathrm{L}^{-1}\right)^{\mathrm{a}}$ & 0 & $<0.05 /<0.05$ & $1.08 / 1.94$ & $2.45 / 2.8$ & $2.9 / 3.2$ & $2.2 / 2.85$ \\
\hline $\mathrm{pH}$ & 7.4 & 7.2 & 7.63 & 7.57 & 7.57 & 7.43 \\
\hline TOC $\left(\mathrm{mg} \mathrm{C} \mathrm{L} \mathrm{L}^{-1}\right)$ & $\leq 0.10$ & 0.35 & 5.54 & 2.75 & 2.82 & 5.13 \\
\hline$\left[\text { Free } \mathrm{Cl}_{2}\right]_{0}\left(\mathrm{mg} \mathrm{Cl}_{2} \mathrm{~L}^{-1}\right)^{\mathrm{b}}$ & 3.0 & 3.0 & 3.0 & 3.0 & 2.9 & 2.8 \\
\hline$\left[\text { Combined } \mathrm{Cl}_{2}\right]_{0}\left(\mathrm{mg} \mathrm{Cl}_{2} \mathrm{~L}^{-1}\right)^{\mathrm{b}}$ & 0 & 0 & 0.7 & 0.4 & 0.3 & 0.8 \\
\hline $\begin{array}{l}\text { Irradiation time for } 50 \% \text { decay } \\
\text { of free } \mathrm{Cl}_{2}(\mathrm{~min})\end{array}$ & 11.75 & 11.75 & 6.0 & 7.5 & 6.5 & 4.5 \\
\hline $\begin{array}{l}\text { UV dose for } 50 \% \text { decay of free } \\
\mathrm{C} 22\left(\mathrm{~kJ} \mathrm{~m}^{-2}\right)\end{array}$ & 12.5 & 12.5 & 7.0 & 8.8 & 7.6 & 5.3 \\
\hline $\begin{array}{l}\text { Irradiation time for a } 90 \% \\
\text { decay of free } \mathrm{Cl}_{2}(\mathrm{~min})\end{array}$ & 35.5 & 35.5 & 17 & 16 & 15.5 & 11 \\
\hline $\begin{array}{l}\text { UV dose for a } 90 \% \text { decay of } \\
\text { free } \mathrm{Cl}_{2}\left(\mathrm{~kJ} \mathrm{~m}^{-2}\right)\end{array}$ & 41.5 & 41.5 & 19.9 & 18.7 & 18.1 & 12.9 \\
\hline $\begin{array}{l}\text { Irradiation time for } 50 \% \text { decay } \\
\text { of combined } \mathrm{Cl}_{2}(\mathrm{~min})\end{array}$ & - & - & 11 & 6.5 & 11 & 7 \\
\hline $\begin{array}{l}\text { UV dose for a } 50 \% \text { decay of } \\
\text { combined } \mathrm{Cl}_{2}\left(\mathrm{~kJ} \mathrm{~m}^{-2}\right)\end{array}$ & - & - & 12.9 & 7.6 & 12.9 & 8.2 \\
\hline $\begin{array}{l}\text { Chlorate yield (mol } \mathrm{ClO}_{3}^{-} \\
\text {formed } / \mathrm{mol} \mathrm{Cl}{ }_{2} \text { decomposed) }\end{array}$ & 0.09 & 0.10 & $\mathrm{nd}^{\mathrm{c}}$ & 0.10 & 0.05 & 0.11 \\
\hline
\end{tabular}

${ }^{a}$ Values measured immediately after the arrival of the samples in the laboratory

${ }^{\mathrm{b}}$ Concentrations determined just before the beginning of the photolysis experiments.

${ }^{\mathrm{c}}$ The concentration could not be determined accurately in this sample. 
Table 2 - Effects of UV treatment (UV dose $=0,23.5$ or $47 \mathrm{~kJ} \mathrm{~m}^{-2}$ ) on the chlorine demands and on the production of DBPs during the postchlorination step (Experimental conditions: see Fig. 1).

\begin{tabular}{|c|c|c|c|c|c|c|c|c|c|c|c|c|}
\hline \multirow{2}{*}{$\frac{\text { Pool water }}{\text { UV Dose }\left(\mathrm{kJ} \mathrm{m}^{-2}\right)}$} & \multicolumn{3}{|c|}{ 0410BLA } & \multicolumn{3}{|c|}{ 0421GAN } & \multicolumn{3}{|c|}{ 0427GAN } & \multicolumn{3}{|c|}{ 0428BEL } \\
\hline & 0 & 23.5 & 47 & 0 & 23.5 & 47 & 0 & 23.5 & 47 & 0 & 23.5 & 47 \\
\hline TOC $\left(\mathrm{mg} \mathrm{C} \mathrm{L} \mathrm{L}^{-1}\right)$ & 5.54 & & & 2.75 & & & 2.82 & & & 5.13 & & \\
\hline $\begin{array}{l}\mathrm{Cl}_{2} \text { demand } \mathrm{mg} \mathrm{Cl}_{2} \mathrm{~L}^{-} \\
\end{array}$ & 1.46 & 2.53 & 2.20 & 0.20 & 1.44 & 1.24 & 0.70 & 1.74 & 1.78 & 0.70 & 2.28 & 2.27 \\
\hline $\operatorname{AOX}\left(\mu \mathrm{g} \mathrm{L}^{-1}\right)$ & 1000 & & 1290 & 510 & & 580 & 500 & & 580 & 1110 & & 1320 \\
\hline Trihalomethanes (TH & Ms) & & & & & & & & & & & \\
\hline $\begin{array}{l}\text { TCM }\left(\mu \mathrm{g} \mathrm{L}^{-1}\right) \\
\text { BDCM }\left(\mu \mathrm{g} \mathrm{L}^{-1}\right) \\
\text { DBCM }\left(\mu \mathrm{g} \mathrm{L}^{-1}\right) \\
\text { TBM }\left(\mu \mathrm{g} \mathrm{L}^{-1}\right) \\
\text { TTHM }\left(\mu \mathrm{g} \mathrm{L}^{-1}\right) \\
\% \text { TTHM in AOX }\end{array}$ & $\begin{array}{c}54.5 \\
6.8 \\
1.6 \\
0.7 \\
63.6 \\
5.41 \\
\end{array}$ & $\begin{array}{c}85.2 \\
14.9 \\
2.6 \\
0.6 \\
103.2\end{array}$ & $\begin{array}{c}100.7 \\
17.5 \\
3.3 \\
0.4 \\
121.8 \\
7.99 \\
\end{array}$ & $\begin{array}{c}31.8 \\
3.6 \\
0.9 \\
0.9 \\
37.2 \\
6.16 \\
\end{array}$ & $\begin{array}{c}70.2 \\
13.4 \\
1.8 \\
0.5 \\
85.9\end{array}$ & $\begin{array}{c}94.9 \\
18.4 \\
1.8 \\
0.4 \\
115.5 \\
16.85 \\
\end{array}$ & $\begin{array}{c}24.7 \\
3.2 \\
0.8 \\
0.4 \\
29.1 \\
4.96 \\
\end{array}$ & $\begin{array}{c}58.3 \\
12.8 \\
2.1\end{array}$ & $\begin{array}{c}82.7 \\
16.5 \\
2.0\end{array}$ & $\begin{array}{c}61.4 \\
5.4 \\
1.2 \\
0.7 \\
68.7 \\
5.33 \\
\end{array}$ & $\begin{array}{c}99.6 \\
15.7 \\
2.9 \\
\text { nd } \\
118.2\end{array}$ & $\begin{array}{c}120.3 \\
20.6 \\
3.2 \\
\text { nd } \\
144.1 \\
9.28 \\
\end{array}$ \\
\hline Haloacetic acids (HA & & & & & & & & & & & & \\
\hline $\begin{array}{l}\text { MCAA }\left(\mu \mathrm{g} \mathrm{L}^{-1}\right) \\
\text { DCAA }\left(\mu \mathrm{g} \mathrm{L}^{-1}\right) \\
\text { TAA }\left(\mu \mathrm{g} \mathrm{L}^{-1}\right) \\
\text { BCAA }\left(\mu \mathrm{g} \mathrm{L}^{-1}\right) \\
\text { DBAA }\left(\mu \mathrm{g} \mathrm{L}^{-1}\right) \\
\text { Total HAA }\left(\mu \mathrm{g} \mathrm{L}^{-1}\right) \\
\% \text { HAAs in AOX }\end{array}$ & $\begin{array}{c}7.8 \\
168.4 \\
183.2 \\
8 \\
<1 \\
367.4 \\
21.8\end{array}$ & $\begin{array}{c}10.2 \\
157.8 \\
187.3 \\
5 \\
<1 \\
360.3\end{array}$ & $\begin{array}{c}8.7 \\
147.2 \\
143.8 \\
7.3 \\
<1 \\
307.0 \\
14.0\end{array}$ & $\begin{array}{c}5.4 \\
116.9 \\
80.41 \\
6.0 \\
<1 \\
208.4 \\
23.75\end{array}$ & $\begin{array}{c}7.8 \\
131.3 \\
78.1 \\
6.5 \\
<1 \\
223.7\end{array}$ & $\begin{array}{c}9.7 \\
138.7 \\
81.5 \\
6 \\
<1 \\
235.9 \\
23.3\end{array}$ & $\begin{array}{c}6.6 \\
138.6 \\
73.6 \\
7.9 \\
<1 \\
226.7 \\
26.0\end{array}$ & $\begin{array}{c}7.5 \\
141.5 \\
70.9 \\
3.7 \\
<1 \\
223.6\end{array}$ & $\begin{array}{c}9.2 \\
159.5 \\
75.5 \\
\\
<1 \\
244.2 \\
24.2\end{array}$ & $\begin{array}{c}18.9 \\
361 \\
135.8 \\
15.5 \\
<1 \\
531.2 \\
27.1\end{array}$ & $\begin{array}{c}20.7 \\
371.7 \\
138.9 \\
\\
<1 \\
531.3\end{array}$ & $\begin{array}{c}21.5 \\
343.8 \\
122.4 \\
8.6 \\
<1 \\
496.3 \\
21.2\end{array}$ \\
\hline $\begin{array}{l}\text { Chloral hydrate }(\mathbf{C H}) \\
\left.\mathrm{CH}(\mu \mathrm{g} \mathrm{L})^{-1}\right) \\
\% \mathrm{CH} \text { in } \mathrm{AOX}\end{array}$ & $\begin{array}{l}363.4 \\
23.4\end{array}$ & 367.0 & $\begin{array}{l}399.4 \\
19.9\end{array}$ & $\begin{array}{l}107.6 \\
13.6\end{array}$ & 140.8 & $\begin{array}{l}154.2 \\
17.1\end{array}$ & $\begin{array}{c}99.6 \\
12.8\end{array}$ & 131.7 & $\begin{array}{l}146.7 \\
16.3\end{array}$ & $\begin{array}{c}378.1 \\
21.9\end{array}$ & 403.7 & $\begin{array}{c}400.3 \\
19.5\end{array}$ \\
\hline $\begin{array}{l}\text { Haloacetonitriles }(\mathbf{H} \\
\text { DCAN }\left(\mu \mathrm{g} \mathrm{L}^{-1}\right) \\
\text { BCAN }\left(\mu \mathrm{g} \mathrm{L}^{-1}\right) \\
\text { DBAN }\left(\mu \mathrm{g} \mathrm{L}^{-1}\right) \\
\text { TCAN }\left(\mu \mathrm{g} \mathrm{L}^{-1}\right) \\
\text { Total HAN }\left(\mu \mathrm{g} \mathrm{L}^{-1}\right) \\
\% \text { HANs in AOX }\end{array}$ & $\begin{array}{l}\text { Ns) } \\
18.6 \\
3.8 \\
0.55 \\
0.06 \\
23.0 \\
1.44\end{array}$ & $\begin{array}{c}29 \\
5.6 \\
0.4 \\
0.06 \\
35.1\end{array}$ & $\begin{array}{c}28.9 \\
6.4 \\
0.24 \\
0.08 \\
35.6 \\
1.73\end{array}$ & $\begin{array}{c}3.4 \\
0.8 \\
0 \\
0 \\
4.2 \\
0.52\end{array}$ & $\begin{array}{c}8.3 \\
2.3 \\
0 \\
0.1 \\
10.7\end{array}$ & $\begin{array}{c}11.9 \\
2.8 \\
0 \\
0.1 \\
14.8 \\
1.60\end{array}$ & $\begin{array}{c}2.8 \\
1 \\
0 \\
0 \\
3.8 \\
0.47\end{array}$ & $\begin{array}{c}7.9 \\
2.8 \\
0 \\
0 \\
10.7\end{array}$ & $\begin{array}{c}10.4 \\
3.1 \\
0 \\
0 \\
13.5 \\
1.45\end{array}$ & $\begin{array}{c}7.1 \\
2.4 \\
0.6 \\
0.8 \\
10.9 \\
0.61\end{array}$ & $\begin{array}{c}13.7 \\
4.7 \\
0 \\
0 \\
18.4\end{array}$ & $\begin{array}{c}15.2 \\
5.7 \\
0 \\
0 \\
20.9 \\
0.98\end{array}$ \\
\hline $\begin{array}{l}\text { Other DBPs } \\
\text { DCP }\left(\mu \mathrm{g} \mathrm{L}^{-1}\right) \\
\text { TCP }\left(\mu \mathrm{g} \mathrm{L}^{-1}\right) \\
\text { TCNM }\left(\mu \mathrm{g} \mathrm{L}^{-1}\right)\end{array}$ & $\begin{array}{l}<0.1 \\
1.5 \\
0.4\end{array}$ & $\begin{array}{l}<0.1 \\
9.1 \\
2.6\end{array}$ & $\begin{array}{l}<0.1 \\
6.2 \\
1.9\end{array}$ & $\begin{array}{l}<0.1 \\
1.0 \\
<0.1\end{array}$ & $\begin{array}{l}0.2 \\
6.9 \\
2.2\end{array}$ & $\begin{array}{c}0.2 \\
13.8 \\
2.2\end{array}$ & $\begin{array}{l}<0.1 \\
<0.3 \\
<0.1\end{array}$ & $\begin{array}{l}<0.1 \\
5.5 \\
1.6\end{array}$ & $\begin{array}{l}0.3 \\
9.1 \\
2.0\end{array}$ & $\begin{array}{c}3.2 \\
11.4 \\
1.0\end{array}$ & $\begin{array}{c}<0.1 \\
22.4 \\
3.3\end{array}$ & $\begin{array}{c}<0.1 \\
28.6 \\
3.8\end{array}$ \\
\hline
\end{tabular}




\section{List of figures}

Fig.1 - Experimental design for UV irradiation and chlorination experiments.

Fig. 2 - Photodecomposition of free chlorine in phosphate-buffered water, tap water and in two pool water samples. a) Concentration-time profiles for free chlorine and b) First-order plots for free chlorine decomposition. $\left([\text { Free chlorine }]_{0}=3.0 \mathrm{mg} \mathrm{L}^{-1}=42 \mu \mathrm{M} ; 25.0^{\circ} \mathrm{C}\right.$; Irradiance $=19.5 \mathrm{~W} \mathrm{~m}^{-2}$ ).

Fig. 3 - Effects of " $\mathrm{UV}+\mathrm{Cl}_{2}$ " pre-treatment $\left(\left[\mathrm{Cl}_{2}\right]_{0}=3 \mathrm{mg} \mathrm{L}^{-1}\right.$; Irradiance $\left.=19.5 \mathrm{~W} \mathrm{~m}^{-2}\right)$ on the chlorine demand of a pool water during post-chlorination (Fig. 3a) and on the concentrations of chloroform (Fig 3a) 1,1,1-trichloropropanone and chloropicrin (Fig. 3b) determined after the postchlorination treatment (Post-chlorination: $\left[\mathrm{Cl}_{2}\right]_{0}=3 \mathrm{mg} \mathrm{L}^{-1}$, Reaction time $=24 \mathrm{~h}, 25.0^{\circ} \mathrm{C}$ ).

Fig. 4 - Effects of the "UV+ $\mathrm{Cl}_{2}$ " pre-treatment of four pool water samples in the presence of free chlorine on the chlorine demands and on the concentrations of DBPs determined after the postchlorination treatment (UV exposure times of 0,20 and 40 min corresponding to $\mathrm{UV}$ doses of $0,23.5$ and $47 \mathrm{~kJ} / \mathrm{m}^{2}$, respectively). 


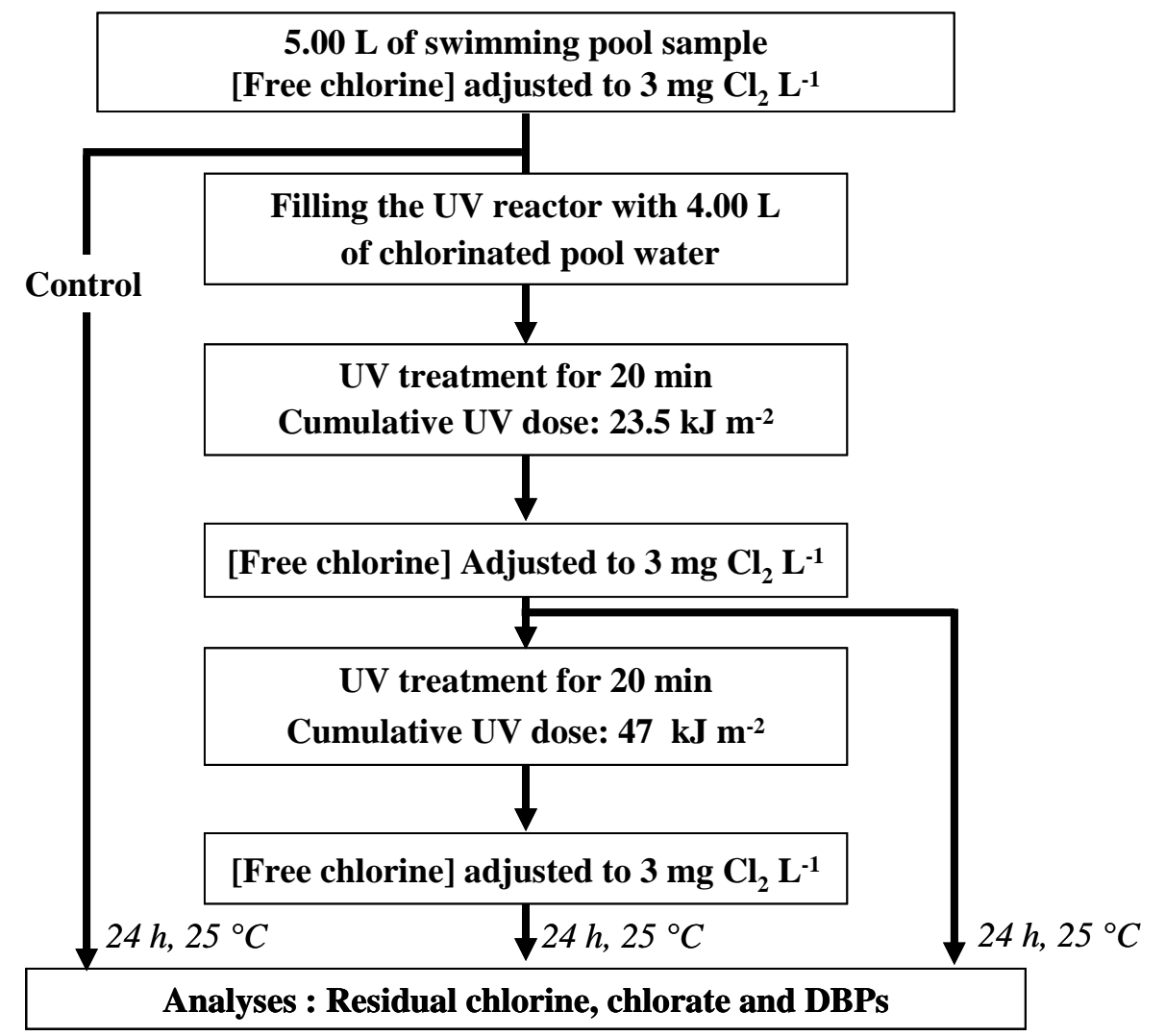

Fig. 1 - Experimental design for UV treatment and chlorination experiments. 

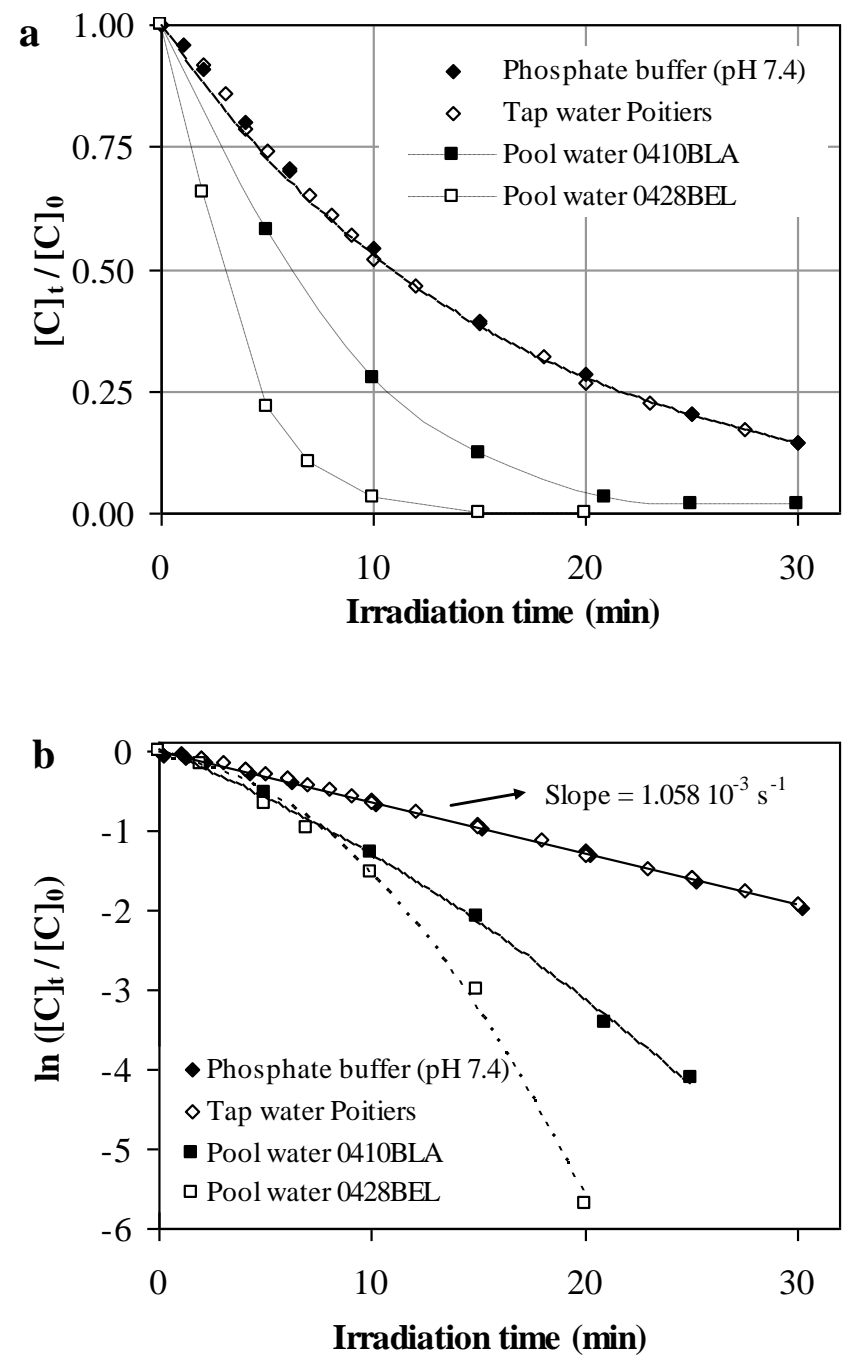

Fig. 2 - Photodecomposition of free chlorine in phosphate-buffered water, tap water and in two pool water samples. a) Concentration time profiles for free chlorine and b): first-order plots for free chlorine decomposition. ([Free chlorine $]_{0}=3.0 \mathrm{mg} \mathrm{L}^{-1}=42 \mu \mathrm{M} ; 25.0^{\circ} \mathrm{C}$; Irradiance $=19.5 \mathrm{~W} \mathrm{~m}^{-2}$ ). 

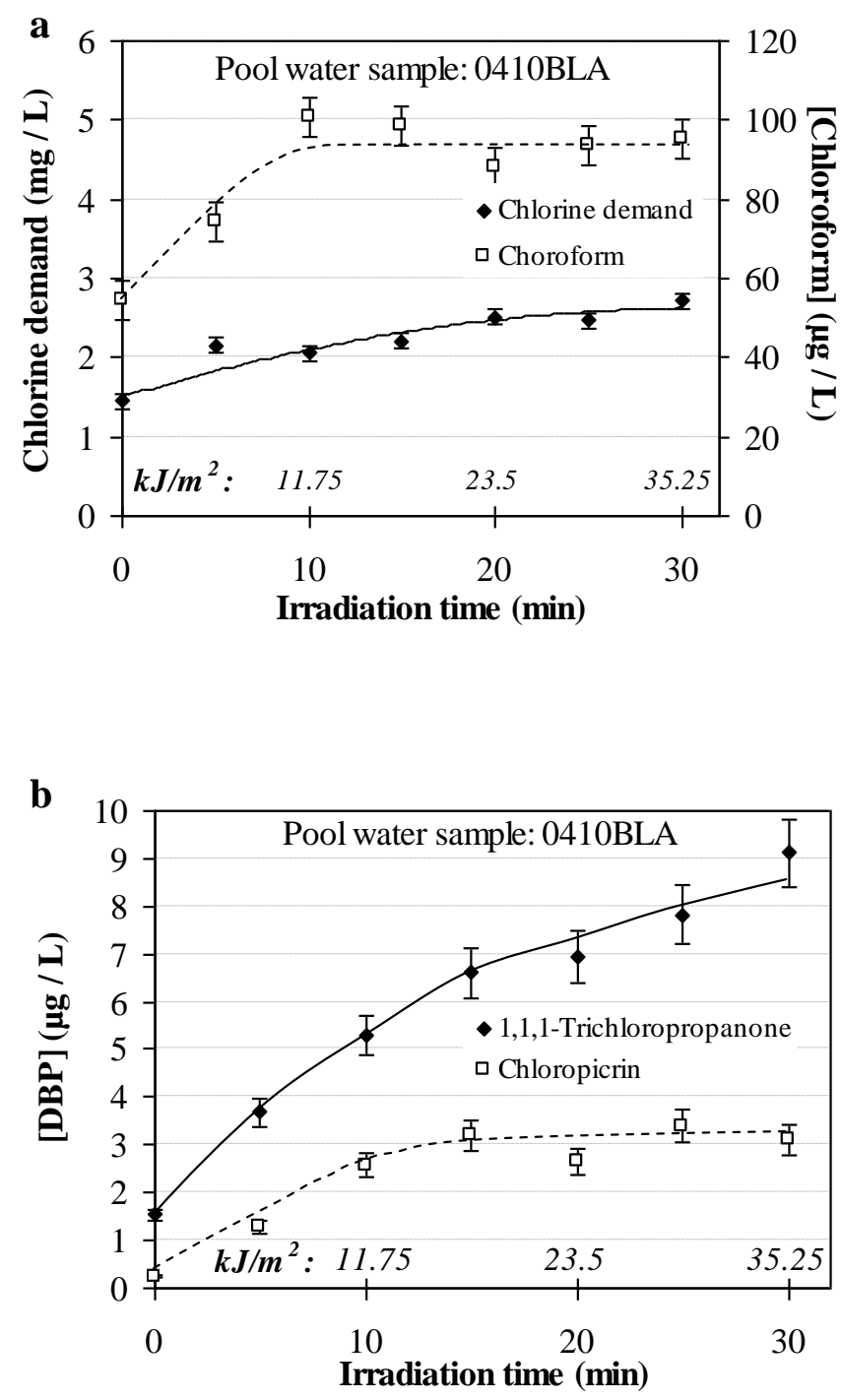

Fig. 3 - Effects of "UV $+\mathrm{Cl}_{2}$ " pre-treatment $\left(\left[\mathrm{Cl}_{2}\right]_{0}=3 \mathrm{mg} \mathrm{L}^{-1}\right.$; Irradiance $\left.=19.5 \mathrm{~W} \mathrm{~m}^{-2}\right)$ on the chlorine demand of a pool water during post-chlorination (Fig. 3a) and on the concentrations of chloroform (Fig 3a) 1,1,1-trichloropropanone and chloropicrin (Fig. 3b) determined after the postchlorination treatment (Post-chlorination: $\left[\mathrm{Cl}_{2}\right]_{0}=3 \mathrm{mg} \mathrm{L}^{-1}$, Reaction time $=24 \mathrm{~h}, 25.0^{\circ} \mathrm{C}$ ). 

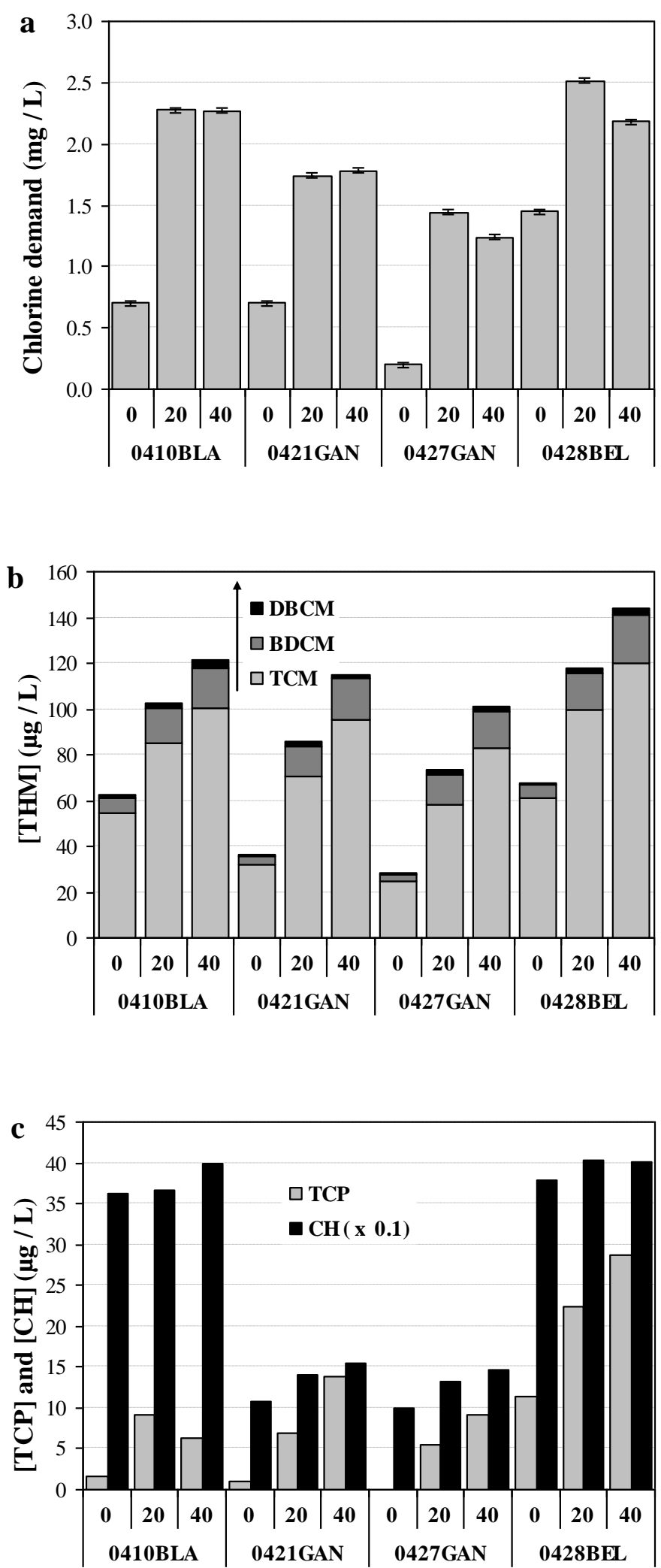


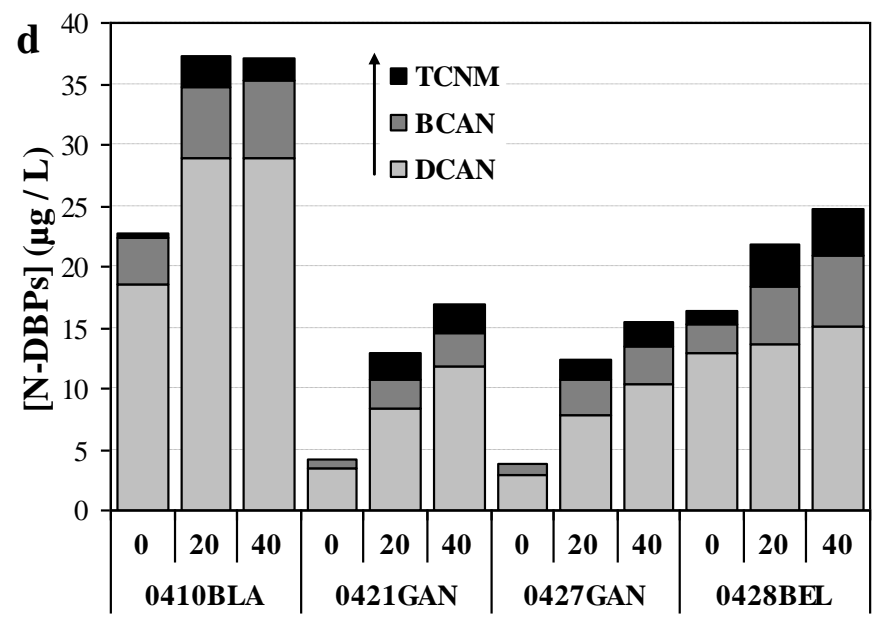

Fig. 4 - Effects of the "UV+ $\mathrm{Cl}_{2}$ " pre-treatment of four pool water samples on the chlorine demands (a) and on the concentrations of DBPs (b-d) determined after the post-chlorination treatment (UV exposure times of 0,20 and 40 min corresponding to UV doses of $0,23.5$ and $47 \mathrm{~kJ} \mathrm{~m}^{-2}$, respectively). 